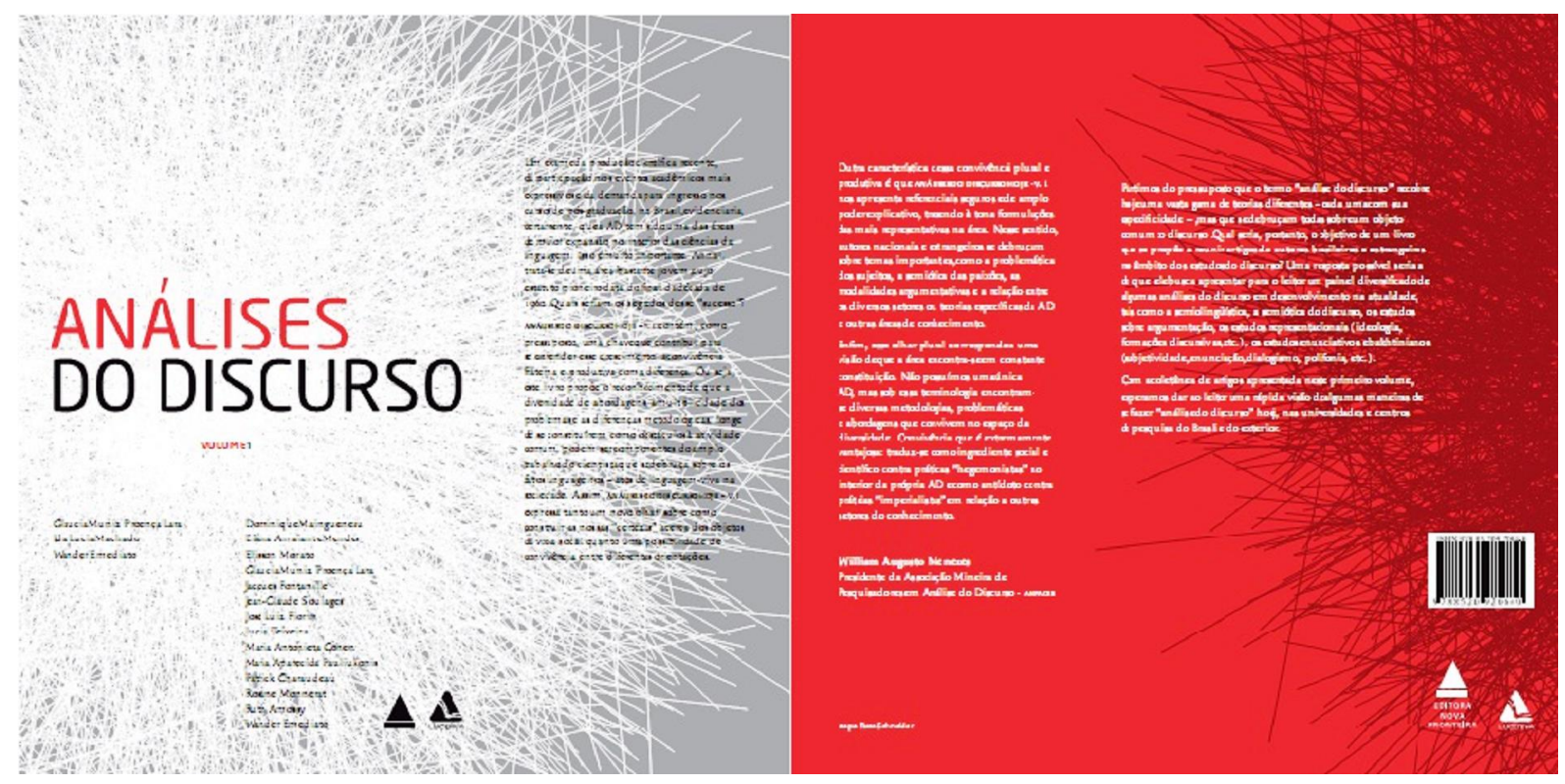

Capa do livro

\title{
Análise ou análises do discurso?
}

\section{William Augusto Menezes}

UFOP/AMPADIS - Associação Mineira de Pesquisadores em Análise do Discurso

LARA, Glaucia Muniz Proença; MACHADO, Ida Lucia; EMEDIATO, Wander (Orgs.). Análises do discurso hoje. Rio de Janeiro: Lucerna/Nova Fronteira, 2008. v. 1.

Quatro décadas após o movimento fundador da Análise do Discurso na França, ganha relevo, entre nós, a publicação deAnálises do discurso hoje, volume 1 - coletânea organizada por Glaucia Muniz Proença Lara, Ida Lucia Machado e Wander Emediato. Os organizadores, todos especialistas em Análise do Discurso e atualmente professores do Programa de Pós-Graduação em Estudos Lingüísticos da UFMG, apresentam como pressuposto da obra o fato de que a Análise do Discurso, enquanto disciplina, metodologia e proposta de conhecimento, ampliou-se bastante nesses 40 anos. No entanto, se hoje a AD se apresenta como um conhecimento bem mais amplo, a obra em foco demonstra que não se trata somente de um crescimento linear. Há mesmo uma consciência de que, se o projeto da Escola Francesa de 
Análise do Discurso foi importante no nascimento da AD, já não parece mais correto falar-se em a Análise do Discurso - aquela que seria a única a se escrever com iniciais maiúsculas. A análise é plural: o mesmo objeto pode ser visto de maneira diversa e, portanto, várias são as teorias e propostas que se apresentam à sua compreensão.

Fiéis a esse postulado, os organizadores trazem-nos contribuições de autores representativos de tendências contemporâneas prestigiadadas nos estudos discursivos, a partir de doze artigos. Patrick Charaudeau (Universidade de Paris XIII), principal teórico e propositor da teoria semiolingüistica, abre a coletânea com "Uma teoria dos sujeitos da linguagem". Trata-se de artigo fundador da teoria em que duas questões ganham realce: i) a descrição, de maneira clara e bastante didática, dos quatro princípios de base do ato de comunicação (princípio de interação,princípio de pertinência, princípio de influência, eprincípio de regulação) e de constituição do "contrato de comunicação"; ii) a apresentação do quadro enunciativo de base, presente em todo ato de comunicação, em que os parceiros (sujeito comunicante e sujeito interpretante), enquanto sujeitos do mundo social, "desdobram-se" em protagonistas do ato de linguagem (sujeito enunciador e sujeito destinatário), enquanto sujeitos do mundo de palavra e, portanto, participantes das estratégias de organização discursiva.

$\mathrm{Na}$ trilha de Patrick Charaudeau, seguem-se os artigos de Eliana Amarante de Mendonça Mendes (UFMG), intitulado "Análise do discurso e tradução", de Maria Aparecida Lino Pauliukonis (UFRJ) e Rosane S. M. Monnerat, (UFF), denominado "Operações discursivas na enunciação", e do próprio Wander Emediato (UFMG), de nome "Os lugares sociais do discurso e o problema da influência, da regulação e do poder nas práticas discursivas". Seria importante, sem dúvida, algum comentário sobre cada um desses trabalhos, mas, no limite que temos, chamaremos a atenção apenas para a novidade teórica que se reveste na temática tratada por Eliana Mendes, na medida em que, a partir da semiolingüistica, a autora procura explorar a interdisciplinaridade entre a Análise do Discurso e a Tradução, vistas até então como áreas desvinculadas.

Jacques Fontanille (Universidade de Limoges) dá início ao segundo conjunto de abordagens, cuja filiação teórica apresenta-se no prolongamento dos trabalhos de Algirdas Julien Greimas e, mais particularmente, no da semiótica das paixões. No artigo em destaque ("A conversão mítico-passional"), o autor, em busca das condições de aparição e desaparição das manifestações afetivas, examina de que modo operam as coerções enunciativas na configuração de três "paixões": a cólera, a piedade e o ciúme. José Luiz Fiorin (USP), também na esteira 
de Greimas, traz uma importante contribuição no artigo intitulado "A semiótica discursiva", em que apresenta um quadro geral desse campo teórico. Glaucia Muniz Porença Lara (UFMG) e Elisson Morato (POSLIN/UFMG) dão continuidade à apresentação de aportes da teoria semiótica, realizando uma aplicação do modelo da semiótica visual (ou plástica) à pintura de Mestre Ataíde, mais especificamente à tela Batismo de Cristo, uma das mais representativas peças do barroco mineiro, que se encontra na Catedral da Sé, em Mariana - MG. Lucia Teixeira (UFF), articulando semiótica tensiva e semiótica visual, apresenta-nos uma outra possibilidade de análise: os textos sincréticos, aqui representados pelos cartazes de cinema, em seu artigo "Achados e perdidos: análise semiótica de cartazes de cinema".

Em outra linha de análise - a da chamada Escola francesa de Análise do Discurso -, encontramos a contribuição de Maria Antonieta Amarante de Mendonça Cohen (UFMG). Abordando questões que se colocavam no início da $A D F$, dentre as preocupações de Michel Pêcheux e Jacques Lacan, e outras bastante contemporâneas, a autora retoma a discussão acerca do sujeito do discurso, em "A questão do sujeito e algumas articulações possíveis: a análise do discurso e a psicanálise". No mesmo quadro teórico, Dominique Maingueneau (Universidade de Paris XII), já bastante conhecido do público brasileiro pela sua perspicácia e pelas contribuições efetivas ao campo da $\mathrm{AD}$, retoma o estudo sobre o discurso religioso e se volta, mais especificamente, para um gênero que muito interessa àqueles que se debruçam sobre esse campo: o sermão.

Outros dois autores estrangeiros participam da coletânea: Ruth Amossy (Universidade de Tel-Aviv) também tem se tornado cada vez mais presente entre os estudiosos brasileiros, principalmente entre os que se dedicam aos estudos sobre a argumentação. Numa visão arrojada, essa autora tem defendido a existência de um programa de estudos que elabore uma teoria da argumentação no discurso, integrando as aquisições da retórica e dos estudos argumentativos às ciências da linguagem contemporâneas. No artigo intitulado "As modalidades argumentativas no discurso", Amossy dedica-se à elaboração da noção de "modalidade argumentativa" e à sua relação com o "registro argumentativo". O último artigo é de Jean-Claude Soulages (Universidade de Lyon II). Soulages, que trabalha juntamente com Patrick Charaudeau nas atividades do Centro de Análise do Discurso - CAD -, é especialista nos estudos discursivos sobre a mídia, principalmente, os estudos televisuais. Em seu artigo, "Instrumentos de análise do discurso nos estudos televisuais", examina programas de auditório na França, a partir de considerações sobre a questão genérica, o dispositivo midiático, a "formatação do olhar" e as orientações persuasivas. 
Após esse quadro de diversidade, em que se contempla a Análise do Discurso nas suas várias vertentes - num quadro incompleto, é claro, mas já aberto a um segundo volume - e em que se percebe o cuidado na análise ampla de corpora (documentos de arquivo, pinturas, cartazes, imaginários etc.), fica ainda mais clara a posição dos organizadores deAnálises do discurso hoje, volume 1: o que importa não é propriamente a questão de que a AD seja plural, mas o fato de que é bem melhor que assim o seja. 